\title{
Acute hemiparesis
}

\section{$A$ rare presentation of spontaneous spinal epidural hematoma mimicking acute stroke}

\author{
Da-Wei Huang, MD, Jui-Ming Sun, MD, Yu-Hao Chen, MD, Kuo-Chang Huang, MD.
}

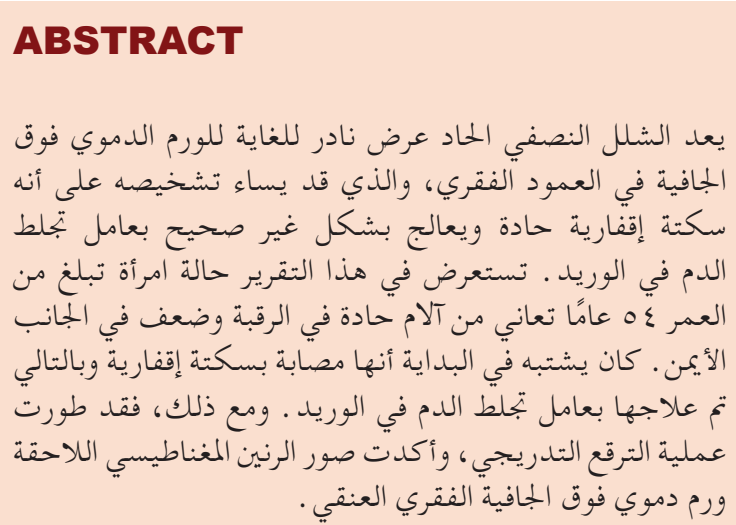

Acute hemiparesis is an extremely rare presentation of spontaneous spinal epidural hematoma, which may be misdiagnosed as acute ischemic stroke and improperly treated with an intravenous thrombolytic agent. Here, we report a case of a 54-year-old woman who presented with acute neck pain and right-sided weakness. She was initially suspected of having ischemic stroke and therefore treated with an intravenous thrombolytic agent. However, she developed progressive tetraparesis, and subsequent magnetic resonance images confirmed cervical spontaneous spinal epidural hematoma.

Neurosciences 2020; Vol. 25 (4): 316-319 doi: 10.17712/nsj.2020.4.20200027

Section of Neurosurgery (Huang, Sun, Chen, Huang), Department of Surgery; from the Chung-Jen Junior College of Nursing, Health Sciences and Management (Chen), Chia-Yi Christian Hospital, Chia-Yi; from the Department of Neurological Surgery (Sun), TriService General Hospital, National Defense Medical Center, Taipei; and from the Department of Biotechnology (Sun), Asia University, Taichung, Taiwan.

Received 2nd March 2020. Accepted 14th June 2020.

Address correspondence and reprint request to: Dr. Kuo-Chang Huang, Section of Neurosurgery, Department of Surgery, Chia-Yi Christian Hospital, Chiayi, Taiwan. E-mail: man58.tw@yahoo.com.tw ORCID ID: https://orcid.org/0000-0003-2698-5103
Stroke is a leading cause of mortality and morbidity $\mathcal{S}_{\text {in Taiwan. }}{ }^{1}$ Acute hemiparesis is one of the most indicative manifestations of acute stroke. Administration of recombinant tissue plasminogen activator (rtPA), a thrombolytic agent, within 3 to 4.5 hours of symptom onset is the standard treatment for acute ischemic stroke. ${ }^{2}$ However, various diseases such as slipped cervical discs, epilepsy, and spinal epidural hematoma may present along with acute hemiparesis, mimicking acute stroke, and thus be inappropriately treated with rtPA. ${ }^{3}$ Spontaneous spinal epidural hematoma (SSEH) is a rare condition of unknown etiology and requires urgent surgical intervention. ${ }^{3-5}$ The characteristic manifestation of SSEH is sudden-onset neck pain following by motor paralysis or tetraparesis. ${ }^{4}$ However, SSEH presenting with acute hemiparesis has been rarely reported in the literature. Therefore, we reported a case of SSEH with acute hemiparesis wrongly treated with rtPA in the emergency department (ED).

Case Report. Patient information. The informed consent was obtained from the patient for the case report. The timeline for this case report was summarized in Table 1. A 54-year-old woman experienced suddenonset neck pain, right facial numbness, and right-sided

Disclosure. The all authors certify that they have NO affiliations with or involvement in any organization or entity with any financial interest (such as honoraria; educational grants; participation in speakers' bureaus; membership, employment, consultancies, stock ownership, or other equity interest; and expert testimony or patent-licensing arrangements), or non-financial interest (such as personal or professional relationships, affiliations, knowledge or beliefs) in the subject matter or materials discussed in this manuscript. 
Table 1 - The timeline for the presented case.

\begin{tabular}{|c|c|c|c|}
\hline Dates & \multicolumn{3}{|c|}{ Relevant past medical history and interventions } \\
\hline & \multicolumn{3}{|c|}{ She denied a history of hypertension, taking anticoagulant/antiplatelet medication, or trauma events. } \\
\hline & Summaries from initial and follow-up visits & Diagnostic testing (including dates) & Interventions \\
\hline $2020 / 1 / 3$ & $\begin{array}{l}\text { - Sudden-onset neck pain, right facial } \\
\text { numbness, and right-sided weakness } \\
\text { - Visiting our ER } 2 \text { hours later after the onset } \\
\text { of symptoms }\end{array}$ & $\begin{array}{l}\text { - Hemoglobin level of } 10.8 \mathrm{mg} / \mathrm{dL} \\
\text { and platelet count of } 263,000 / \mu \mathrm{L} \text {. } \\
\text { (2020/1/3) } \\
\text { - A coagulation test produced } \\
\text { normal results. }(2020 / 1 / 3) \\
\text { - A computed tomography }(\mathrm{CT}) \\
\text { scan of the brain revealed no } \\
\text { intracranial hemorrhage. CT } \\
\text { angiography revealed no evidence } \\
\text { of major vessel occlusion or artery } \\
\text { dissection. }(2020 / 1 / 3)\end{array}$ & $\begin{array}{l}\text { - Intravenous recombinant tissue plasminogen } \\
\text { activator (rtPA) was administrated within } 4.5 \\
\text { hours of symptom onset. }(2020 / 1 / 3)\end{array}$ \\
\hline $2020 / 1 / 3$ & $\begin{array}{l}\text { Left-side weakness developed } 3 \text { hours later } \\
\text { rtPA injection }\end{array}$ & $\begin{array}{l}\text { - Subsequent magnetic resonance } \\
\text { images of the brain and cervical spine } \\
\text { revealed a mass in the right dorsal } \\
\text { portion of the cervical canal above } \\
\text { the C3 level that was compressing } \\
\text { the spinal cord }(2020 / 1 / 3)\end{array}$ & $\begin{array}{l}\text { - Emergent laminectomy with hematoma } \\
\text { removal } 12 \text { hours after symptom onset. } \\
(2020 / 1 / 3)\end{array}$ \\
\hline $2020 / 1 / 8$ & $\begin{array}{l}\text { The motor strength of the left extremities } \\
\text { recovered to grade } 4\end{array}$ & & \\
\hline $2020 / 1 / 21$ & $\begin{array}{l}\text { Discharge with right extremities recovered to } \\
\text { grade } 3\end{array}$ & & \\
\hline $2020 / 2 / 5$ & She could walk with walker & & \\
\hline
\end{tabular}

weakness. After these symptoms had persisted for 2 hours, she visited our ED. She denied a history of hypertension, taking anticoagulant/antiplatelet medication, or trauma events.

Clinical findings. On arrival, she was alert and cognizant. Her vital signs were as follows: blood pressure of $113 / 73 \mathrm{~mm} \mathrm{Hg}$ (normal range: $90 / 60 \mathrm{mmHg}$ to $120 / 80 \mathrm{mmHg}$ ), heart rate of 74 beats per minute (normal range: 60 to 100 beats per minute), respiratory rate of 20 breaths per minute (normal range: 12 to 16 breaths per minute), and body temperature of $36.1^{\circ} \mathrm{C}$ (normal range: 36.1 to 37.2 ). Neurological examination revealed Grade 2 (of 5) muscle power in the right extremities, normal deep tendon reflexes, and a right Babinski sign. Cranial nerve function was normal, except for decreased sensation on the right side of the face. Laboratory examination revealed a hemoglobin level of $10.8 \mathrm{mg} / \mathrm{dL}$ (normal range: $12-15.5 \mathrm{mg} / \mathrm{dl}$ ) and platelet count of $263,000 / \mu \mathrm{L}$ (normal range: 150,000 to $450,000 / \mathrm{uL}$ ). A coagulation test produced normal results. An emergency computed tomography (CT) scan of the brain revealed no intracranial hemorrhage. CT angiography revealed no evidence of major vessel occlusion or artery dissection. Her National institutes of health stroke scale was 11 (normal range: 0 to 42 ). As acute ischemic stroke is highly suspected with right hemiparesis, intravenous rtPA was administrated within 4.5 hours of symptom onset.

Diagnostic assessment. However, the right side progressively weakened after rtPA administration, and left-side weakness developed 3 hours later. The patient remained alert and oriented. Grade 2 (of 5) muscle power was found in the left extremities. Subsequent magnetic resonance (MR) images of the brain and cervical spine revealed a mass in the right dorsal portion of the cervical canal above the C3 level that was compressing the spinal cord (Figure 1A). The mass was isointense on T1-weighted images (Figure 1B) and hyperintense on T2-weighted images (Figure 1C).

Therapeutic intervention. With a diagnosis of cervical SSEH, the patient underwent emergent laminectomy with hematoma removal 12 hours after symptom onset. The hematoma was located primarily on the dorsal aspect of the right spinal canal above the C3 level and was severely compressing the spinal cord (Figure 2). Pathological examination confirmed the diagnosis of hematoma without vascular abnormality. The intraoperative blood loss was $50 \mathrm{~mL}$. 
(A)

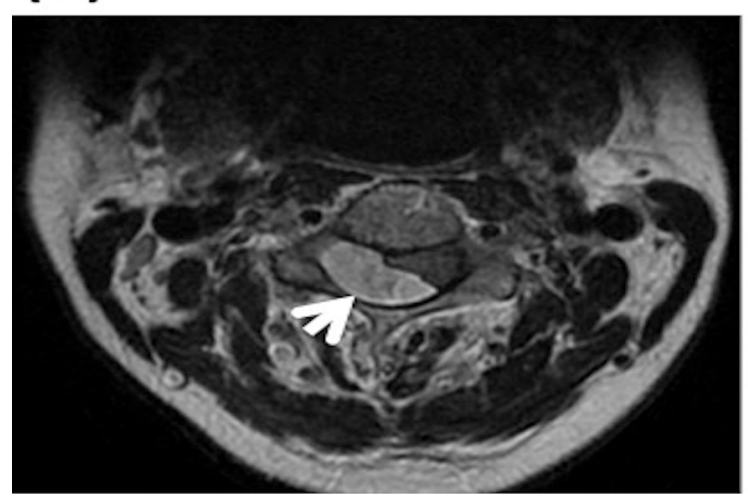

(B)

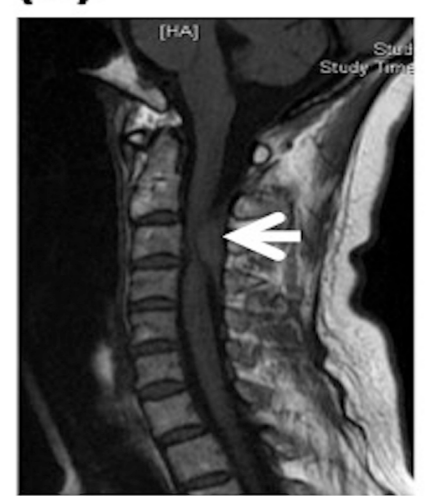

(C)

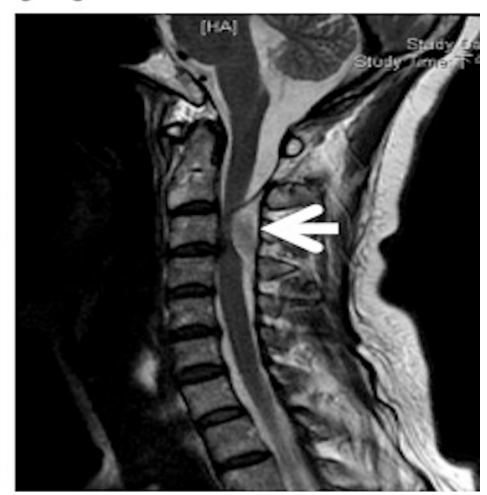

Figure 1 - Magnetic resonance images of the cervical spine showing A) Axial T2-weighted image shows a mass (white arrow) in the right dorsal portion of the cervical canal above the C3 level, compressing the spinal cord. B) Sagittal T1-weighted image shows mass isointensity (white arrow). C) Sagittal T2-weighted image shows high mass intensity (white arrow).

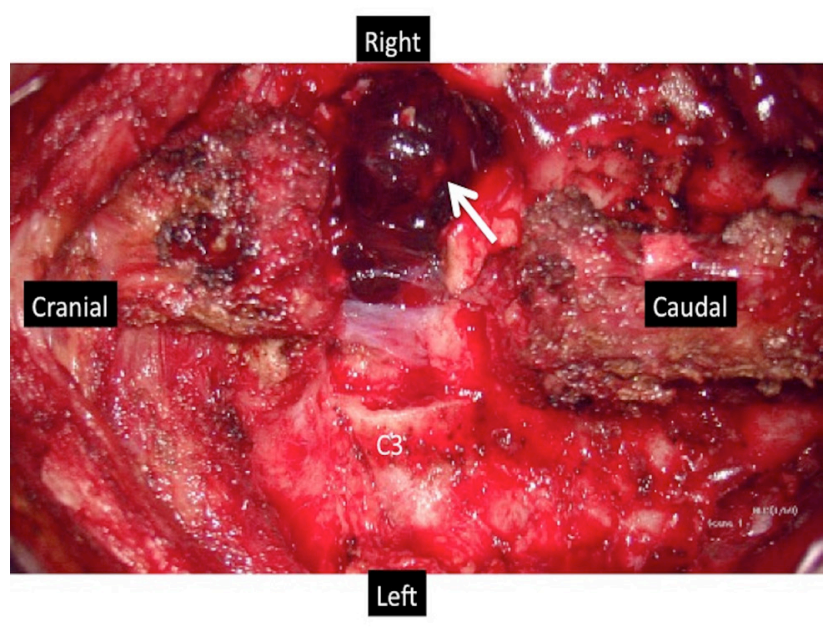

Figure 2 - Intraoperative view following laminectomy; hematoma (white arrow) mainly located on the right dorsal aspect of the C3 region.

Follow-up and outcomes. Postoperatively, her neurological deficits decreased gradually. On the fifth postoperative day, the motor strength of the left extremities recovered to grade 4 . The motor strength of the right extremities recovered to grade 3 at discharge. She could walk with the walker one month after the surgery.

Discussion. Spontaneous spinal epidural hematoma is a rare etiology of acute hemiparesis that can cause spinal cord compression. The annual incidence of SSEH is approximately 0.1 per 100,000 , and most cases are observed in men aged between 50 and 80 years. ${ }^{4}$ Spontaneous spinal epidural hematoma is caused by many factors, such as hypertension, coagulopathy, anticoagulant/antiplatelet therapy, neoplasm, hemodialysis, vascular abnormality, and idiopathic causes. ${ }^{3,5}$ Although the pathophysiological mechanism is unclear, bleeding in SSEH has been hypothesized to be associated with activities resulting in a sudden increase in posterior epidural venous pressure, such as cough, sneezing, twisting, lifting, and straining. ${ }^{3-6}$

Patients with cervical SSEH commonly present with sudden-onset neck pain and subsequent rapid motor paralysis or sensory dysfunction. ${ }^{7}$ However, acute hemiparesis has been reported to be an extremely rare presentation of SSEH. ${ }^{5,8,9}$ Such cases may be initially misdiagnosed as acute ischemic stroke, which commonly presents with acute hemiparesis and is treated with intravenous thrombolytic agents in the ED. ${ }^{5,8,10} \mathrm{Kim}$ et $\mathrm{al}^{3}$ showed that $2(22.2 \%)$ of 9 patients initially misdiagnosed with ischemic stroke and treated with intravenous rtPA actually had SSEH. Clinical manifestations such as Horner syndrome, BrownSequard syndrome, and the absence of cranial nerve palsies in acute hemiparesis indicate SSEH rather than stroke; after observing such manifestations, Patel et al ${ }^{9}$ showed that 13 patients suspected of having stroke and treated with heparin, rtPA, or warfarin actually had SSEH. Furthermore, Matsumoto et $\mathrm{al}^{8}$ concluded that initial symptoms of neck pain and the Lhermitte sign are the most crucial for distinguishing SSEH from acute ischemic stroke.

The soft tissue window of a CT scan may enable physicians to rule out cerebrovascular or cardiovascular disease and identify SSEH. ${ }^{11}$ Magnetic resonance imaging is the standard method for diagnosing SSEH and can help determine the location, contours, and severity 
of cord compression. ${ }^{4}$ In the acute stage, hematoma commonly appears as an isosignal on T1-weighted MR images and a high signal on T2-weighted MR images. ${ }^{4,7}$ Enhanced MR imaging or MR angiography may be helpful in differentiating SSEH from other disorders presenting with hemiparesis, including ischemic stroke, prolapsed cervical discs, epidural abscesses, neoplasms, or transverse myelitis. ${ }^{9}$

Although few cases (mainly from pediatric patients) with spontaneous resolution following conservative treatment have been described, ${ }^{12-14}$ decompressive laminectomy with hematoma evacuation is the standard care procedure for patients with SSEH presenting with neurological deficitis. ${ }^{4,9,11}$ The outcome is correlated with the delay from symptom onset until surgical intervention. ${ }^{9}$ Surgical decompression after more than 12 hours of profound deficits may cause permanent neurological disability. ${ }^{15}$ However, the effects of rtPA on the surgical outcome and intraoperative bleeding tendency are unclear because few SSEH patients are treated with intravenous rtPA. ${ }^{10}$ In our case, the operation was performed 8 hours after intravenous rtPA treatment, and the intraoperative blood loss was only $50 \mathrm{~mL}$. Thus, the effect of one-time intravenous rtPA administration on surgical intervention is negligible. In patient's perspective, cervical SSEH must be considered when sudden onset of neck pain following by motor weakness occurs, without obvious cranial nerve abnormalities such as facial palsy or tongue deviation.

In conclusion, although acute hemiparesis is the main presentation of acute stroke in the ED, cervical SSEH must be considered when a patient presents with neck pain but no obvious cranial nerve abnormalities, such as facial palsy or tongue deviation. Improper use of rtPA may cause cervical SSEH to progress, delay surgical intervention, and worsen the surgical outcome.

Acknowledgement. We would like to thank Dr. Cheng-Ta Hsieh (Sijhih Cathay General Hospital, New Taipei, Taiwan) for providing assistance in the preparation of the manuscript.

\section{References}

1. Hsieh FI, Chiou HY. Stroke: morbidity, risk factors, and care in taiwan. J Stroke 2014; 16: 59-64.
2. Adams HP Jr., Brott TG, Furlan AJ, Gomez CR, Grotta J, Helgason CM, et al. Guidelines for thrombolytic therapy for acute stroke: A supplement to the guidelines for the management of patients with acute ischemic stroke. A statement for healthcare professionals from a Special Writing Group of the Stroke Council, American Heart Association. Stroke 1996; 27: 1711-1718.

3. Kim MC, Kim SW. Improper Use of thrombolytic agents in acute hemiparesis following misdiagnosis of acute ischemic stroke. Korean J Neurotrauma 2018; 14: 20-23.

4. Hsieh CT, Chang CF, Lin EY, Tsai TH, Chiang YH, Ju DT. Spontaneous spinal epidural hematomas of cervical spine: report of 4 cases and literature review. Am J Emerg Med 2006; 24: 736-740.

5. Lee CH, Kwun KH, Jung KH. Spontaneous spinal epidural hematoma treated with tissue plasminogen activator mimicking ischemic stroke. Interdisciplinary Neurosurgery 2020; 19: 100569.

6. Zhang S, Geng F, Wang J, Zhang Z, Du C. Rapid Recovery of Spontaneous Spinal Epidural Hematoma without Surgical Treatment: Case Report and Literature Review. World Neurosurg 2018; 115: 216-219.

7. Hsu SY, Chang CJ, Hsieh CT. Brown-Sequard syndrome: a rare presentation of spontaneous cervical spinal epidural haematoma. Hong Kong Journal of Emergency Medicine 2014; 21: 107-111.

8. Matsumoto H, Miki T, Miyaji Y, Minami H, Masuda A, Tominaga S, et al. Spontaneous spinal epidural hematoma with hemiparesis mimicking acute cerebral infarction: two case reports. J Spinal Cord Med 2012;35:262-266.

9. Patel R, Kumar A, Nishizawa K, Kumar N. Hemiparesis in spontaneous spinal epidural haematoma: a potential stroke imitator. BMJ Case Rep 2018; 2018.

10. Son S, Kang DH, Choi DS, Kim SK, Lim BH, Choi NC. A case of spontaneous spinal epidural hematoma mimicking a stroke. Neurologist 2012; 18: 41-43.

11. Eto F, Tatsumura M, Iwabuchi S, Ogawa T, Mammoto T, Hirano A. Clinical features of spontaneous spinal epidural hematoma. J Rural Med 2019; 14: 206-210.

12. Tender GC, Awasthi D. Spontaneous cervical spinal epidural hematoma in a 12-year-old girl: case report and review of the literature. J La State Med Soc 2004; 156: 196-198.

13. Fattahi A, Taheri M. Spontaneous resolved cervical spine epidural hematoma: A case report. Surg Neurol Int 2017; 8: 183.

14. Zhang B, Chen J, Zou N, Wang L, Wang H, Jiang J, et al. Spontaneous resolution and complete recovery of spontaneous cervical epidural hematoma: Report of two cases and literature review. Neurochirurgie 2019; 65: 27-31.

15. Lawton MT, Porter RW, Heiserman JE, Jacobowitz R, Sonntag VK, Dickman CA. Surgical management of spinal epidural hematoma: relationship between surgical timing and neurological outcome. J Neurosurg 1995; 83: 1-7. 